\title{
Acid-catalyzed reactions of hexanal on sulfuric acid particles: Identification of reaction products
}

\author{
Rebecca M. Garland $^{\mathrm{a}, \mathrm{b}}$, Matthew J. Elrod ${ }^{\mathrm{c}}$, Kristi Kincaid ${ }^{\mathrm{a}}$, Melinda R. Beaver ${ }^{\mathrm{a}, \mathrm{b}}$, \\ Jose L. Jimenez ${ }^{\mathrm{a}, \mathrm{b}}$, Margaret A. Tolbert ${ }^{\mathrm{a}, \mathrm{b}, *}$ \\ ${ }^{a}$ Department of Chemistry and Biochemistry, University of CO, Boulder, CO 80309, USA \\ ${ }^{\mathrm{b}}$ CIRES, University of CO, Boulder, CO 80309, USA \\ ${ }^{\mathrm{c}}$ Department of Chemistry and Biochemistry, Oberlin College, Oberlin, OH 44074, USA
}

Received 26 August 2005; received in revised form 4 March 2006; accepted 4 March 2006

\begin{abstract}
While it is well established that organics compose a large fraction of the atmospheric aerosol mass, the mechanisms through which organics are incorporated into atmospheric aerosols are not well understood. Acid-catalyzed reactions of compounds with carbonyl groups have recently been suggested as important pathways for transfer of volatile organics into acidic aerosols. In the present study, we use the aerodyne aerosol mass spectrometer (AMS) to probe the uptake of gasphase hexanal into ammonium sulfate and sulfuric acid aerosols. While both deliquesced and dry non-acidic ammonium sulfate aerosols showed no organic uptake, the acidic aerosols took up substantial amounts of organic material when exposed to hexanal vapor. Further, we used ${ }^{1} \mathrm{H}-\mathrm{NMR}$, Fourier transform infrared (FTIR) spectroscopy and GC-MS to identify the products of the acid-catalyzed reaction of hexanal in acidic aerosols. Both aldol condensation and hemiacetal products were identified, with the dominant reaction products dependent upon the initial acid concentration of the aerosol. The aldol condensation product was formed only at initial concentrations of $75-96 \mathrm{wt} \%$ sulfuric acid in water. The hemiacetal was produced at all sulfuric acid concentrations studied, $30-96 \mathrm{wt} \%$ sulfuric acid in water. Aerosols up to $88.4 \mathrm{wt} \%$ organic $/ 11.1 \mathrm{wt} \% \mathrm{H}_{2} \mathrm{SO}_{4} / 0.5 \mathrm{wt} \%$ water were produced via these two dimerization reaction pathways. The UV-VIS spectrum of the isolated aldol condensation product, 2-butyl 2-octenal, extends into the visible region, suggesting these reactions may impact aerosol optical properties as well as aerosol composition. In contrast to previous suggestions, no polymerization of hexanal or its products was observed at any sulfuric acid concentration studied, from 30 to $96 \mathrm{wt} \%$ in water.
\end{abstract}

(C) 2006 Elsevier Ltd. All rights reserved.

Keywords: Troposphere; Organic aerosols; Acid-catalyzed reactions; Product identification

\footnotetext{
*Corresponding author. Department of Chemistry and Biochemistry, University of CO, Boulder, CO 80309, USA.

E-mail address: Margaret.Tolbert@colorado.edu (M.A. Tolbert).
}

\section{Introduction}

The composition of atmospheric aerosols impacts their optical and hygroscopic properties, cloud condensation ability and chemical reactivity in heterogeneous reactions. While ambient aerosols can be up to $80 \%$ by mass organic (Saxena and 
Hildemann, 1996; Middlebrook et al., 1998; Molnar et al., 1999; Turpin et al., 2000), it is not well understood how the organic mass is incorporated into the aerosol, nor its speciation. For an organic compound to condense on a seed aerosol the compound's vapor pressure must be less than $\sim 10^{-5} \mathrm{~atm} \quad(10 \mathrm{ppm})$ and less than $\sim 10^{-9} \mathrm{~atm}$ (1 ppb) for the vapor to self-nucleate (Kamens et al., 1999). These values are much lower than the vapor pressure of many organic compounds found in the atmosphere. For example, Jang and Kamens (2001) have suggested that when considering the vapor pressure and accommodation coefficient of aldehydes, those with less than eight carbons should not partition into existing particles. Even for organic compounds with low vapor pressures, modeling results indicate that growth of nuclei by simple condensation of pure organic vapors may not be viable due to the large Kelvin effect of such small particles (Zhang and Wexler, 2002). Recently, co-nucleation of sulfuric acid and aromatic acids has been demonstrated as a mechanism for forming mixed organic/sulfate particles (Zhang et al., 2004). Another possible mechanism by which certain high vapor pressure organics are incorporated into acidic particles is via acid-catalyzed reactions (Jang et al., 2002; Zhang and Wexler, 2002).

In addition to providing a mechanism for secondary organic aerosol formation, acid-catalyzed reactions can potentially impact the optical properties of aerosols. For example, UV-VIS spectra of the acid-catalyzed reaction products of acetaldehyde and isoprene have been found to have absorption features which extend to visible wavelengths (Limbeck et al., 2003; Noziere and Esteve, 2005). The addition of light-absorbing organic material into atmospheric aerosols may have important consequences in the aerosol direct effect on climate change.

Acid-catalyzed reactions of carbonyl-containing organic compounds, such as aldehydes, are well known in bulk solutions (Carey and Sundberg, 1990; Vollhardt and Schore, 1994). However, it is not clear if such reactions occur in sub-micrometer sulfuric acid particles exposed to trace organics in the gas phase. Some field studies have reported increased particle mass in air parcels where both sulfuric acid and organic concentrations were high, indicating that acid-catalyzed reactions may occur (Brock et al., 2003; Chu et al., 2004). For example, it has been found that in power plant plumes where $\mathrm{SO}_{2}$ concentrations are high and the volatile organic compound (VOCs) concentrations are low, the observed particle growth can be accounted for by $\mathrm{SO}_{2}$ oxidation alone (Brock et al., 2002). However, when both $\mathrm{SO}_{2}$ and VOC concentrations were elevated, particle growth exceeded that which could be explained by $\mathrm{SO}_{2}$ oxidation alone; suggesting the VOCs are incorporated into the aerosols (Brock et al., 2003). However, other field studies have not found a significant difference between the organic mass concentrations between periods when ambient sulfate aerosols were acidic or neutralized (Zhang et al., 2005). Thus, laboratory studies are needed to evaluate the potential importance of this type of reaction in the atmosphere.

Previous laboratory studies have found increased organic mass incorporated into acidic solutions as compared to non-acidic solutions for various gaseous aldehydes (Iraci and Tolbert, 1997; Jang and Kamens, 2001; Jang et al., 2003a, b, 2002; Michelsen et al., 2004; Liggio et al., 2005; Zhao et al., 2005); ketones (Jang et al., 2003a, b; Noziere and Riemer, 2003); oxidation products of isoprene, acrolein and $\alpha$-pinene (Czoschke et al., 2003; Iinuma et al., 2004; Tolocka et al., 2004); and isoprene itself (Limbeck et al., 2003). Many studies have suggested that in order for the organic vapors to be incorporated into the aerosol, oligomerization or polymerization must occur (Jang and Kamens, 2001; Czoschke et al., 2003; Jang et al., 2003a, b, 2002, 2005; Kalberer et al., 2004; Tolocka et al., 2004; Noziere and Esteve, 2005). However, while it is clear that acidic aerosols take up more organic mass than non-acidic aerosols, the identification of reaction pathways (if a reaction is indeed occurring) and identification of specific molecular products in these studies has been incomplete. FTIR spectroscopy has been utilized to identify functional groups (Iraci and Tolbert, 1997; Jang and Kamens, 2001; Czoschke et al., 2003; Jang et al., 2003a, b, 2002), though it is difficult to identify specific products through IR spectroscopy. Gas chromatography techniques have also been used in identifying specific reaction products (Jang et al., 2003a, b; Noziere and Riemer, 2003), however not all acidcatalyzed reaction products are stable in a GC column; thus gas chromatography cannot solely be used to identify products. Various mass spectrometry techniques have also been used to show evidence of polymerization and identify the reaction products (Iinuma et al., 2004; Kalberer et al., 2004; Tolocka et al., 2004; Liggio et al., 2005). However, identifying reaction products via these techniques is 
not trivial as fragmentation often creates complicated spectra. In the current study, a variety of techniques was used to identify specific molecular reaction products when gas-phase hexanal was exposed to acidic and non-acidic aerosols.

Hexanal is prevalent in the atmosphere and has both primary sources, such as vegetation and the cracking of petroleum, as well as secondary sources such as the oxidation of longer chain organics (Kesselmeier and Staudt, 1999; Kawamura et al., 2000; Tadic et al., 2001; Muller et al., 2002). The relatively high vapor pressure of hexanal, $0.01 \mathrm{~atm}$, suggests that it should not partition into the particle phase to any significant extent. An increase to a 12 carbon compound, which is the smallest product of an acid-catalyzed reaction of hexanal, will decrease the vapor pressure by a factor of $\sim 10^{4}$ (Barsanti and Pankow, 2004). Thus, hexanal is an ideal acidcatalyzed reaction system, as the parent aldehyde is too volatile to partition greatly into a particle, while the possible dimer reaction products have lower vapor pressures that should favor the organic partitioning to the aerosol. In early work from Barsanti and Pankow (2004) the aldol condensation reaction of hexanal was deemed not thermodynamically favorable, however recent work (Barsanti and Pankow, 2005) indicates that the reaction is actually more thermodynamically favorable than first thought. Below we describe an experiment using the aerodyne aerosol mass spectrometer (AMS), Fourier transform infrared spectroscopy (FTIR), UV-VIS spectroscopy, ${ }^{1} \mathrm{H}$ NMR and GC/MS to probe the reaction of hexanal vapor with sulfuric acid and ammonium sulfate particles.

\section{Experimental}

Fig. 1 shows a schematic diagram of the aerosol generation and sampling apparatus used in the present study. All experiments were performed at room temperature. Sub-micron sulfuric acid and ammonium sulfate aerosols were produced using an atomizer (TSI Model 3076) with a syringe pump (Harvard Apparatus 22). The ammonium sulfate solution atomized was $23 \mathrm{wt} \%$ ammonium sulfate/ $77 \mathrm{wt} \%$ water. Argon was used as the atomization and carrier gas in all the experiments in order to remove the $\mathrm{N}_{2}$ interference at $m / z$ 28. After production, the aerosols were then passed over a sulfuric acid conditioning bath, if necessary, to set the water vapor pressure in the sulfuric acid experiments or to dry the ammonium sulfate particles. The composition of the sulfuric acid aerosols after atomization and conditioning was verified with the FTIR (Anthony et al., 1995; Bertram et al., 1996) to be consistent with the solutions atomized, when no conditioning bath was used, or the concentration of the conditioning bath used. Hexanal vapor was produced by passing room temperature argon over a room temperature hexanal bath. The partial pressures of hexanal used in this study (0.004-0.009 atm) are larger than ambient levels and were used to compensate for short exposure times. The sulfate particles and organic vapor were combined in the mixing cell and then entered two 4-liter mixing cells setting the residence time of the experiment to $13 \mathrm{~min}$. The resulting particles were then sampled in-line through the AMS (Aerodyne Inc., MA (Jayne et al., 2000; Jimenez et al., 2003)) or collected into a volume of

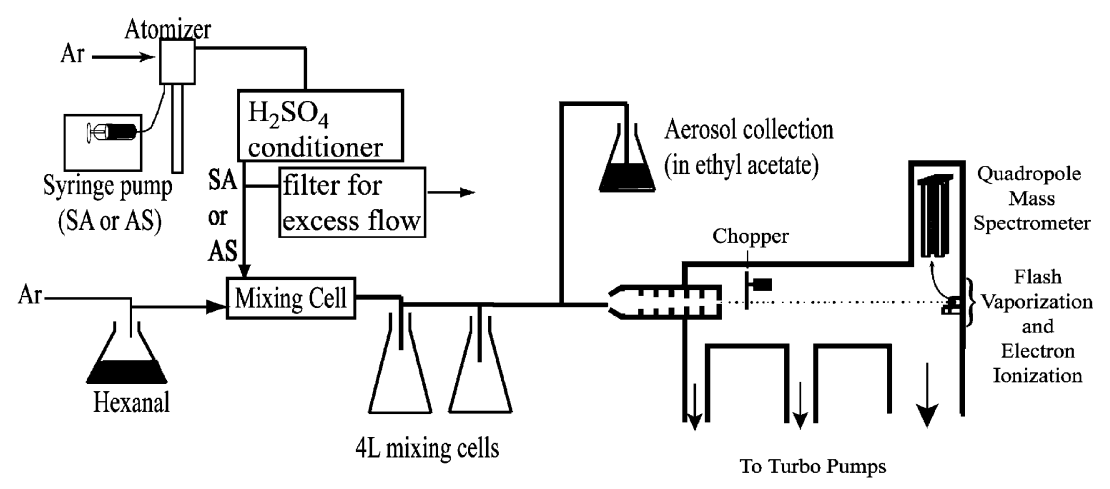

Fig. 1. Schematic of experimental apparatus. Sulfuric acid (SA) and ammonium sulfate (AS) aerosols are generated with an atomizer and then mixed with hexanal vapor. Mixed particles are analyzed in situ using the aerodyne aerosol mass spectrometer (AMS) or are collected in ethyl acetate for off-line characterization with ${ }^{1} \mathrm{H}-\mathrm{NMR}$, FTIR, GC-MS or UV-VIS. 
ethyl acetate for four hours. All chemicals were purchased through Sigma-Aldrich.

A full description of the Aerodyne AMS has been published elsewhere (Jayne et al., 2000; Jimenez et al., 2003). Briefly, particles entering this AMS are preferentially focused over gases by a factor of $\sim 10^{7}$. The particles pass through a particle time of flight (PTOF) region at the end of which they strike a vaporizer $\left(\sim 600^{\circ} \mathrm{C}\right)$. The vaporized molecules enter into the electron impact ionization region, and the positive ions formed are mass analyzed with a quadrupole mass spectrometer. Since ionization occurs under high vacuum, ion-molecule reactions are suppressed and quantitative information on the mass loading at each $\mathrm{m} / z$ can be obtained. To give such quantitative information, the absolute ionization efficiency of the AMS for nitrate is routinely calibrated with pure monodisperse $\mathrm{NH}_{4} \mathrm{NO}_{3}$ particles. The concentrations of other species are quantified by using "relative ionization efficiencies" (RIEs) determined during calibration experiments with those species (Alfarra et al., 2004). Organic species of many different types have very similar RIEs around 1.4 (Takegawa et al., 2005; Zhang et al., 2005). Together with the RIEs and comparing the collected mass spectrum to known fragmentation patterns, the mass from specific species (i.e. sulfates, organics, nitrates) can be identified (Allan et al., 2004). Identification of specific compounds is generally very difficult however, as fragmentation of the molecular ion is too great. Aerosol sizing is achieved by chopping the particle beam upon entering the PTOF chamber and then recording the time as the ions from the vaporized particles hit the detector. If a gaseous compound is present in large concentrations, such as the carrier gas argon, a gaseous trace will be seen in the PTOF at sizes smaller than the particle traces. Thus, using the PTOF it is possible to determine the phase of the measured organics. By recording the ion signals as a function of particle size, the ensemble chemical composition of each size particle can be determined. The transmission efficiency of the lens leads to decreased transmission efficiency of small particles $(<60 \mathrm{~nm})$ and large particles $(>600 \mathrm{~nm})$.

In addition to the AMS measurements of the hexanal uptake products, a detailed chemical analysis was performed on collected particles. Ammonium sulfate particles and sulfuric acid particles were produced and mixed with hexanal vapor as described above, and were then bubbled into $\sim 200 \mathrm{~mL}$ of ethyl acetate. This volume is large compared to the organic material collected $(\sim 1 \mathrm{mg})$, ensuring that chemical reactions would not continue throughout sampling, as gas-phase hexanal was not removed prior to sampling. A blank, where hexanal vapor was bubbled into a solution of $\sim 200 \mathrm{~mL}$ ethyl acetate and $1 \mathrm{mg}$ sulfuric acid, was performed to ensure no reaction was occurring after collection. Aerosols were collected for $4 \mathrm{~h}$ to obtain sufficient material for both ${ }^{1} \mathrm{H}-\mathrm{NMR}$ and GC-MS analysis. The solution was washed with distilled water and then a sodium chloride solution to remove the sulfates. Finally, the organic fraction was concentrated on a rotary evaporator and the resulting organic oil was analyzed through ${ }^{1} \mathrm{H}-\mathrm{NMR}$ and GC-MS (HP 5890A GC-MS). ${ }^{1} \mathrm{H}-\mathrm{NMR}$ analysis was performed on a $500 \mathrm{MHz}$ Varian Instrument and all chemical shifts are reported relative to the solvent $\left(\mathrm{CDCl}_{3}, \delta=7.27 \mathrm{ppm}\right)$. Chemical shifts and integrations were compared to literature values where available and a 2D-COSY experiment was run to determine coupling (Martin and Zektzer, 1988; Bruch, 1996).

The organic fraction was diluted with hexanes for GC-MS analysis and then $1 \mu \mathrm{L}$ of the solution was injected into the GC column. The sample was eluted off a $25 \mathrm{~m}$ HP-5 column (crosslinked 5\% PH ME Siloxane, Hewlett Packard Inc) with an inner diameter of $0.25 \mathrm{~mm}$ and a film thickness of $0.25 \mu \mathrm{m}$. The GC-MS was operated using a temperature profile with a starting temperature of $40{ }^{\circ} \mathrm{C}$, then ramped by $15^{\circ} \mathrm{C}$ per minute to an end temperature of $300^{\circ} \mathrm{C}$. Satellite FTIR spectroscopy and UV-VIS spectroscopy (Hewlett Packard 8452A) were also employed to characterize the reaction products.

\section{Results and discussion}

\subsection{Uptake results}

Laboratory studies were performed on the uptake of hexanal into sulfuric acid aerosols of initial concentrations 30, 50, 75 and $96 \mathrm{wt} \% \mathrm{H}_{2} \mathrm{SO}_{4}$ in water. The uptake of hexanal on ammonium sulfate aerosols was used as a control. In each case, the Aerodyne AMS was used to quantify the organic fraction of the aerosol and to gain initial insight into the identity of the reaction products. Fig. 2 shows the mass spectra of pure ammonium sulfate aerosols and ammonium sulfate aerosols exposed to $0.009 \mathrm{~atm}$ of hexanal vapor. The two spectra are very similar indicating very little, if any, uptake of 


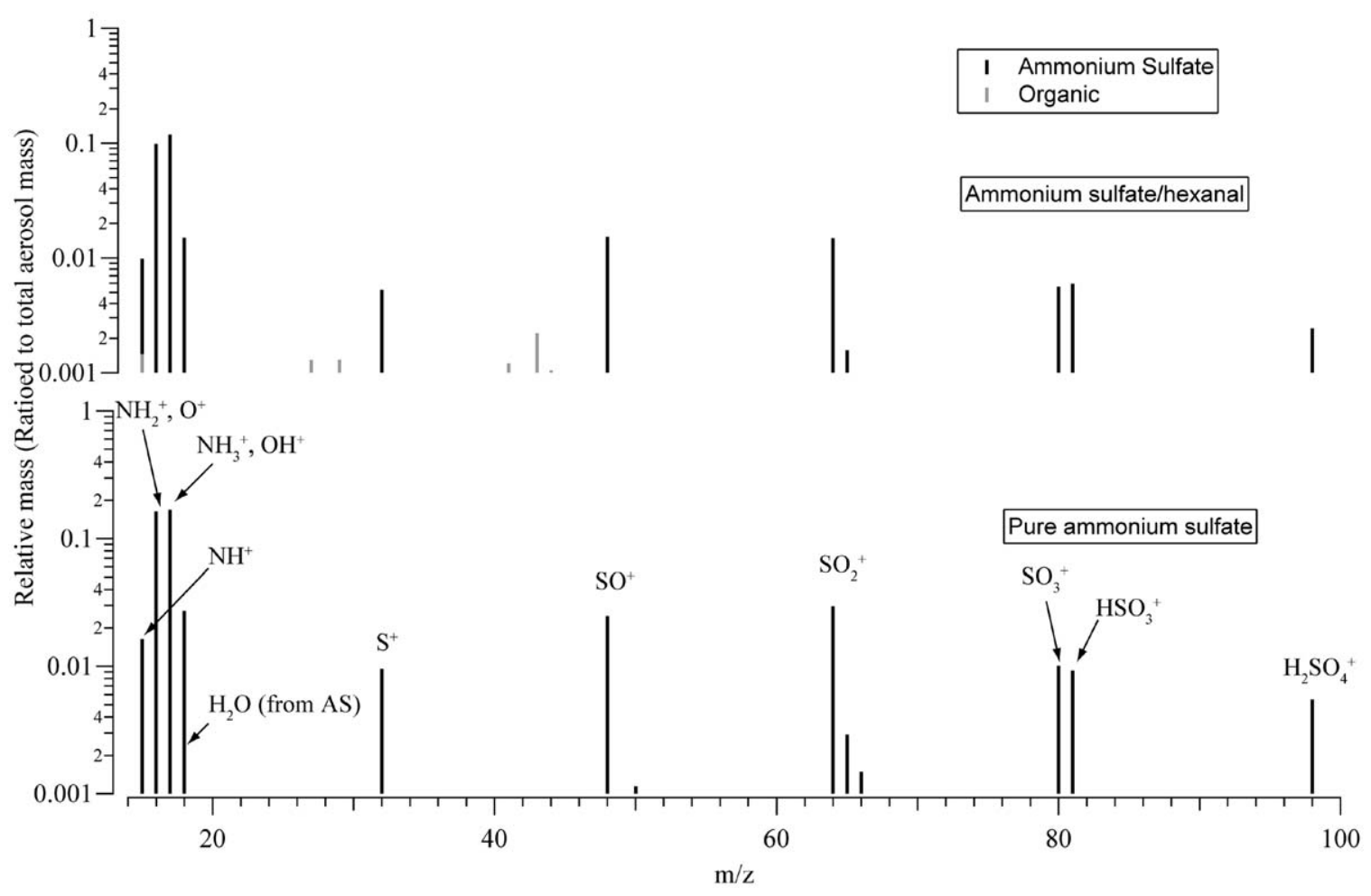

Fig. 2. Mass spectra from the AMS of pure ammonium sulfate aerosols (bottom) and ammonium sulfate aerosols exposed to 0.009 atm hexanal (top). The black lines are the peaks attributed to sulfate and the gray are attributed to organic mass fragments. The main peaks attributed to ammonium sulfate are labeled; all other ammonium sulfate peaks are isotope fragments.

hexanal by the ammonium sulfate particles. While the mass spectrum of ammonium sulfate aerosols exposed to hexanal does contain traces of organic material, the particle time of flight (PTOF) analysis for these species indicates that the organic material was mostly present in the gas phase, and not the particle phase. Both deliquesced $(\sim 23 \mathrm{wt} \%$ ammonium sulfate in water) and dry $(\mathrm{RH}<30 \%)$ ammonium sulfate aerosols were exposed to hexanal vapor and the mass spectra from the two cases were virtually identical. In addition, analysis of the mass spectra in Fig. 2 revealed that all major peaks were due to ammonium sulfate.

Fig. 3 displays the mass spectra when aerosols with an initial concentration of $75 \mathrm{wt} \% \mathrm{H}_{2} \mathrm{SO}_{4} /$ $25 \mathrm{wt} \% \mathrm{H}_{2} \mathrm{O}$ were exposed to varying amounts of hexanal. The organic peaks in the pure sulfuric aerosol are most likely due to small amounts of organic contamination that are prevalent in the atomization of sulfuric acid (Middlebrook et al., 1997). The contamination is negligible compared to the organic mass incorporated into the aerosols upon exposure to hexanal vapor. In contrast to the ammonium sulfate results, a large amount of organic material is incorporated into the acidic aerosols. Analysis of the mass spectral fragments in this case reveals peaks that are due to both sulfuric acid and organics. As the partial pressure of hexanal vapor increases, the amount of organic incorporated into the aerosol increases as evidenced by the increase in particle organic mass fragments. The ratios of organic to sulfate mass concentrations as measured by the Aerodyne AMS for all the sulfuric acid concentrations studied, as well as ammonium sulfate, are shown in Fig. 4. It can be seen that all of the sulfuric acid aerosols took up much more organic material than the ammonium sulfate aerosols. Further, increasing sulfuric acid concentration leads to more organic material being incorporated into the particle.

The amount of organic matter in the sulfuric acid aerosols exposed to hexanal vapor is higher than would be predicted solely on hexanal's water solubility. The low solubility of hexanal in water would lead to a saturated solution at $0.6 \mathrm{wt} \%$ hexanal $/ 99.4 \mathrm{wt} \%$ water. The organic/sulfate ratio from the mass spectrum of ammonium sulfate aerosols exposed to $0.009 \mathrm{~atm}$ hexanal indicates 


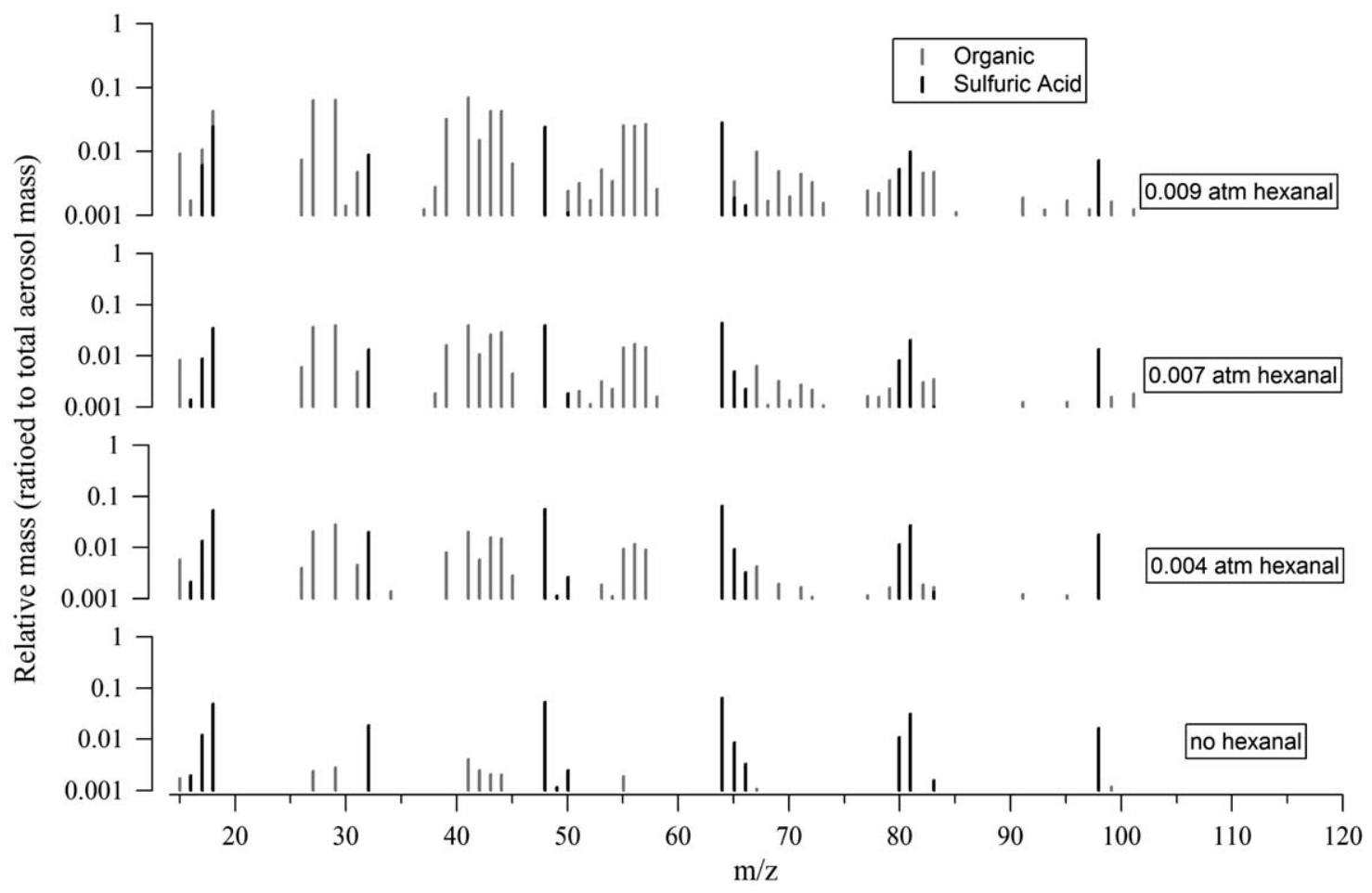

Fig. 3. Mass spectra of $75 \mathrm{wt} \%$ sulfuric acid aerosols exposed to varying pressures of hexanal vapor.

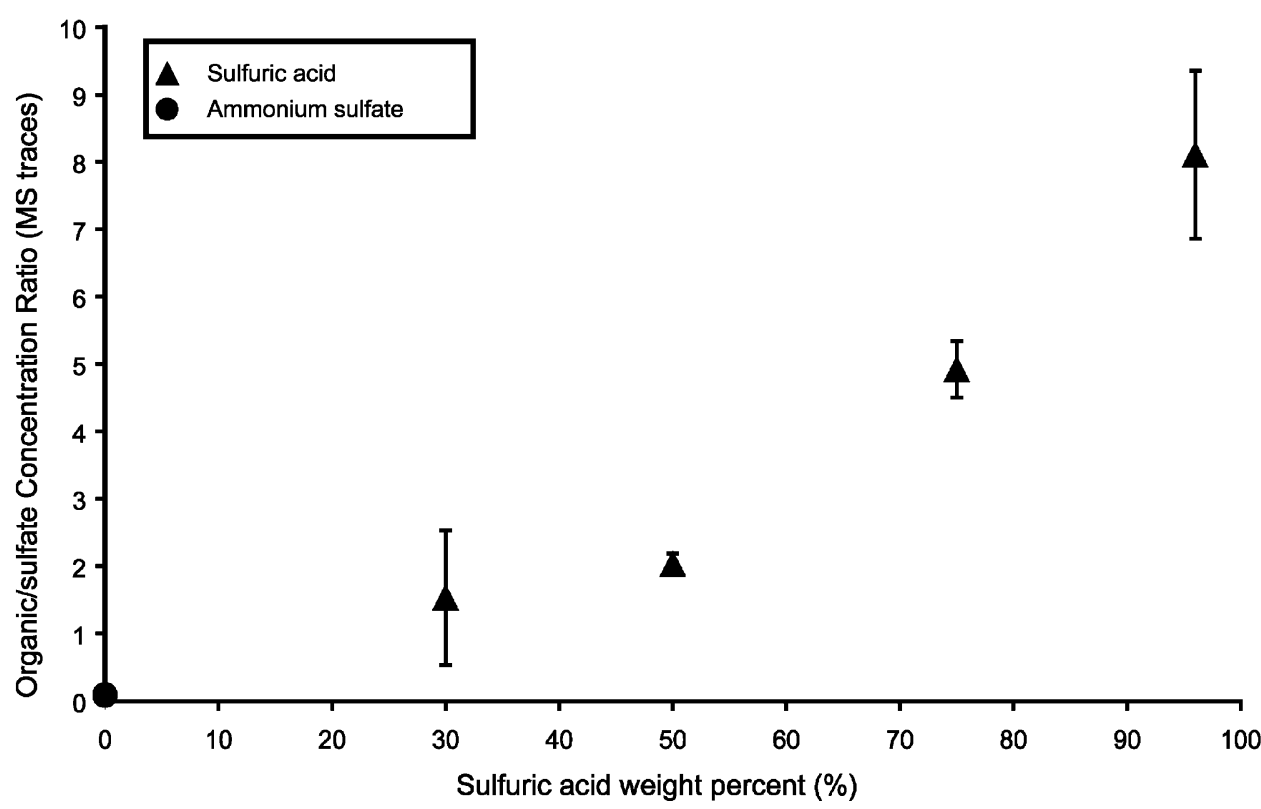

Fig. 4. Uptake of organics as a function of initial sulfuric acid weight percent. The triangles are sulfuric acid and the circle is ammonium sulfate. All points are at hexanal pressure of $0.009 \mathrm{~atm}$. Error bars are \pm 1 standard deviation.

that a solution of $1.7 \mathrm{wt} \%$ organic $/ 22.6 \mathrm{wt} \%$ ammonium sulfate $/ 75.7 \mathrm{wt} \%$ water was created. However, as the PTOF indicates that much of the organic is in the gas phase, this is an upper limit. In a sulfuric acid aerosol with an initial concentration of $96 \mathrm{wt} \%$ acid in water, the observed organic/ 
sulfate ratio of 8.11 is equivalent to $88.4 \mathrm{wt} \%$ organic/ $11.1 \mathrm{wt} \% \quad \mathrm{H}_{2} \mathrm{SO}_{4} / 0.5 \mathrm{wt} \%$ water. Thus, the addition of sulfuric acid greatly increases the amount of organic in solution. Previous studies have found that in mildly acidic solutions $(<50 \mathrm{wt} \%$ acid), carbonyl compounds have a lower solubility than in water (Noziere and Riemer, 2003; Michelsen et al., 2004). However, in our study, all concentrations of sulfuric acid show greatly increased organic content over that of water, thus suggesting that the uptake is not solely due to physical dissolution, but rather a chemical reaction is occurring.
In addition to observing more organic mass with increasing sulfuric acid concentration, the AMS detects particle growth when organic vapor is present. Fig. 5 displays the PTOF size distributions for $50 \mathrm{wt} \% \mathrm{H}_{2} \mathrm{SO}_{4} / 50 \mathrm{wt} \% \mathrm{H}_{2} \mathrm{O}$ aerosols before and after exposure to $0.009 \mathrm{~atm}$ of hexanal vapor. In the size distribution for the sulfuric acid aerosols, Fig. $5 \mathrm{a}$, only the ion fragments from sulfuric acid are detected in the particles. After exposure to organic vapors, however, the particles contain both organics and sulfuric acid. The organic and sulfuric acid traces have the same size distribution, thus strongly suggesting that these species are internally mixed in
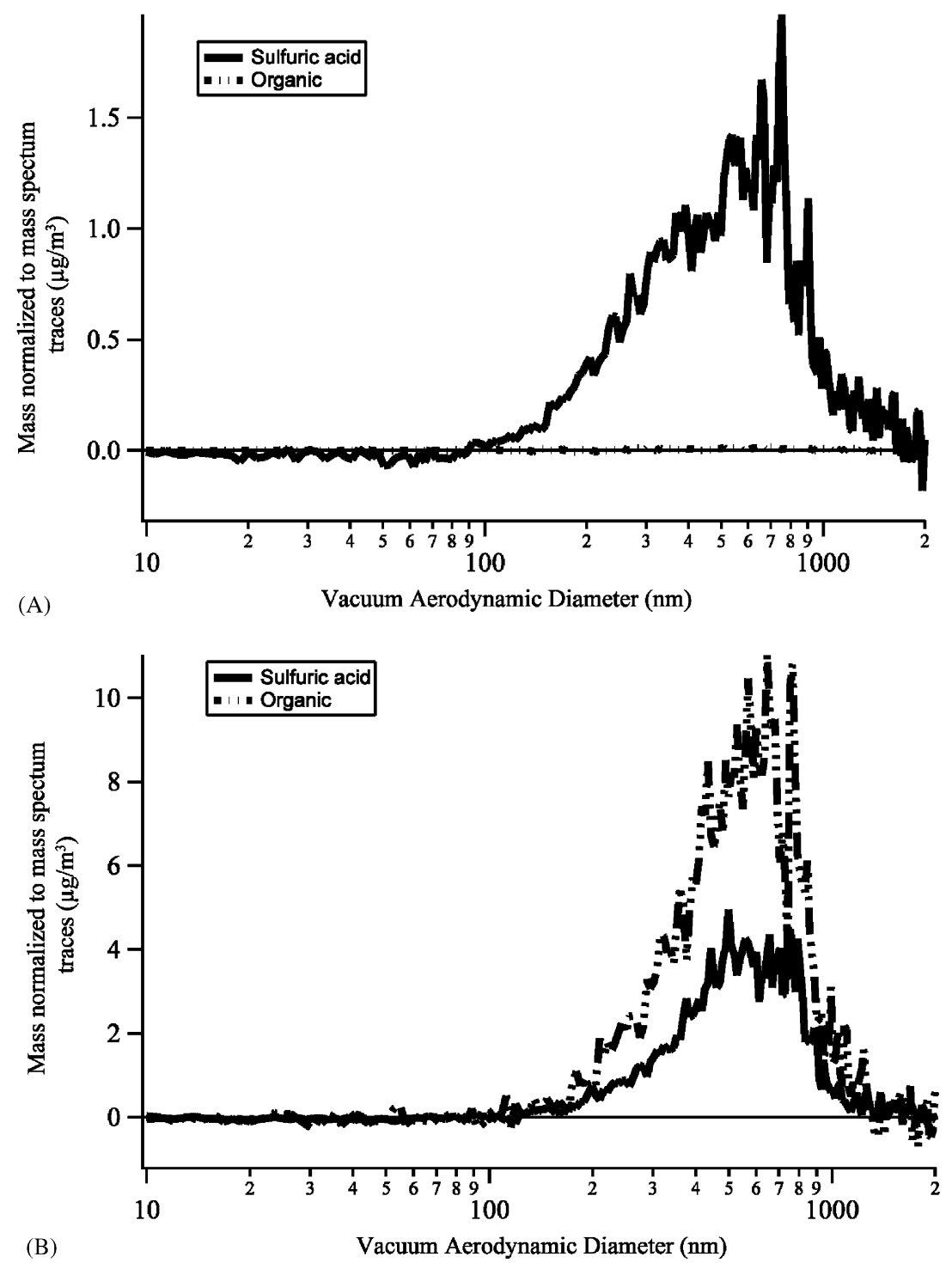

Fig. 5. TOF size distribution for (A) $50 \mathrm{wt} \% \mathrm{H}_{2} \mathrm{SO}_{4} / 50 \mathrm{wt} \% \mathrm{H}_{2} \mathrm{O}$ aerosols and (B) aerosols with the initial concentration of $50 \mathrm{wt} \%$ $\mathrm{H}_{2} \mathrm{SO}_{4} / 50 \mathrm{wt} \% \mathrm{H}_{2} \mathrm{O}$ after exposure to $0.009 \mathrm{~atm}$ hexanal. 
the same particle. An increase in diameter is also seen when the acidic aerosols are exposed to hexanal. In Fig. 5 an increase from a mode diameter of $512 \mathrm{~nm}$ for $50 \mathrm{wt} \%$ sulfuric acid in water aerosols (panel A) to a mode diameter of $550 \mathrm{~nm}$ occurs after exposing the same aerosols to $0.009 \mathrm{~atm}$ hexanal (panel B). Even though quantifying growth through the PTOF size distributions is difficult as the size distributions are broad and not lognormal, the growth seen in the PTOF is generally consistent with the increase in mass seen in the mass spectra. PTOF size distributions for ammonium sulfate aerosols exposed to hexanal vapor show no particle traces attributable to organics within the detection limit of the instrument; only gas-phase organic traces are present.

\subsection{Identification of reaction products}

While the AMS data show greatly increased uptake of hexanal vapor for acidic aerosols, the identity of the organic material in the aerosol cannot be determined from the AMS mass spectra alone. To determine if a reaction occurs within the aerosol, ${ }^{1} \mathrm{H}-\mathrm{NMR}$ and GC-MS were utilized. Several possible reaction pathways for hexanal in the presence of an acid catalyst are shown in Scheme 1 . In reaction pathway I, aldol condensation, hexanal reacts with its enol form and in acidic conditions dehydrates to form the conjugated aldol product. Pathway II shows the formation of a hemiacetal product through reaction of hexanal with its hydrated form. It has been suggested that this hemiacetal can continue to react to form a polymer (Jang et al., 2002). The third pathway shows the equilibrium of hexanal with its trimer. A small amount of trimer is always present in the hexanal solution, and its formation may be stabilized in the presence of an acid. The oxidation of hexanal to hexanoic acid can occur as well. However, this oxidation reaction results in a

I. Aldol condensation

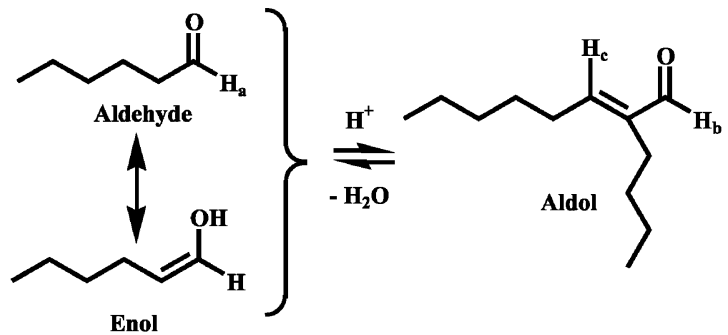

II. Hemiacetal/polymerization

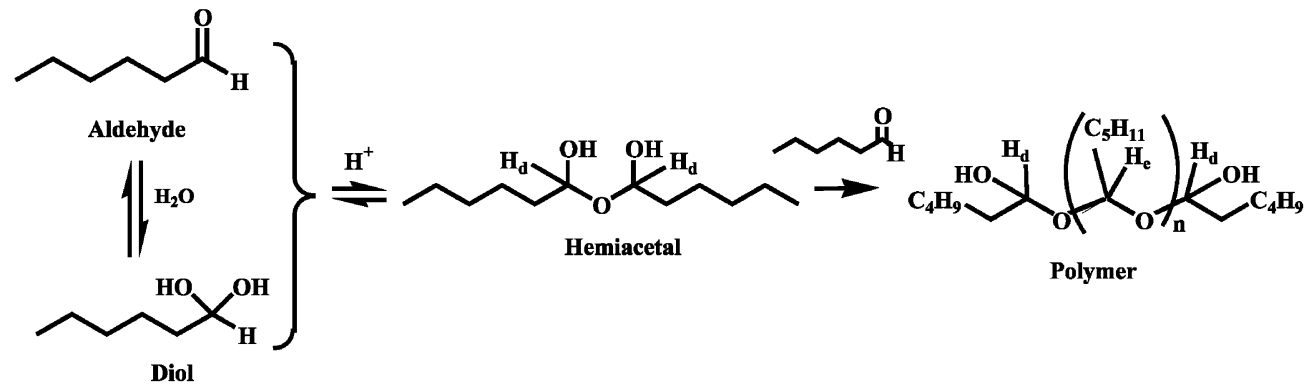

III. Trimerization

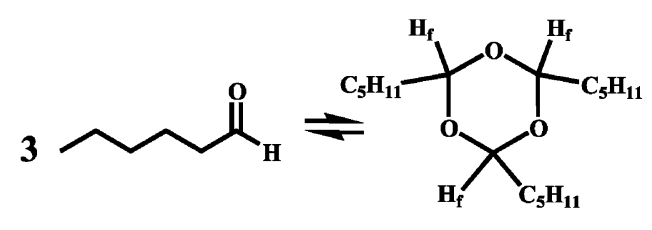

Aldehyde

Trimer

Scheme 1. Possible reaction pathways for hexanal in the presence of sulfuric acid. 


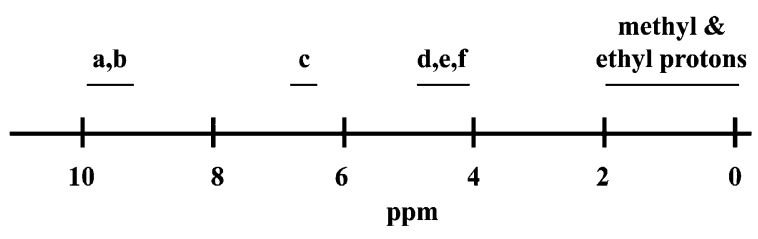

Fig. 6. Expected chemical shifts of all protons in hexanal and reaction products. The letters correspond to the labeled protons in Scheme 1.

product with a vapor pressure of $10^{-4} \mathrm{~atm}$, which is too high to partition greatly into the particle phase. Thus, oxidation of the aldehyde is generally not considered as a pathway to increase the organic mass in a particle; only accretion reactions will result in an increase in organic mass (Barsanti and Pankow, 2004). As some of the expected products are not thermally stable in the GC column, ${ }^{1} \mathrm{H}-$ NMR proved to be the most useful technique for identifying products. The GC-MS data were then used to determine the number of compounds in the samples and verify the ${ }^{1} \mathrm{H}-\mathrm{NMR}$ results.

Fig. 6 displays the expected chemical shifts for hexanal and its products, the letters corresponding to the labeled protons in Scheme 1. Before aerosols were collected and analyzed, bulk solutions of the same initial concentrations of sulfuric acid used in the aerosol study $\left(30,50,75,96 \mathrm{wt} \% \mathrm{H}_{2} \mathrm{SO}_{4}\right.$ in water) were mixed with liquid hexanal and the reaction products analyzed. These products were then used as standards for possible reaction products that may occur in the collected aerosol. Fig. 7A, B and C show part of the ${ }^{1} \mathrm{H}-\mathrm{NMR}$ spectra obtained for bulk hexanal, the bulk reaction product of hexanal in $50 \mathrm{wt} \% \mathrm{H}_{2} \mathrm{SO}_{4} / 50 \mathrm{wt} \% \mathrm{H}_{2} \mathrm{O}$, and the bulk reaction product of hexanal in $96 \mathrm{wt} \%$ $\mathrm{H}_{2} \mathrm{SO}_{4} / 4 \mathrm{wt} \%$ water, respectively. The region of the spectra shown is where differences in the products can be seen in the ${ }^{1} \mathrm{H}-\mathrm{NMR}$. At chemical shifts lower than those shown, the three spectra look similar due to peaks corresponding to $\mathrm{CH}_{2}$ and $\mathrm{CH}_{3}$ protons. Table 1 displays the predicted splitting and integration of the lettered protons in hexanal and its reaction products indicated in Scheme 1. This information was compared between the bulk and aerosol ${ }^{1} \mathrm{H}-\mathrm{NMR}$ spectra in order to identify reaction products.

The characteristic peak of hexanal is the aldehyde proton $\left(H_{\mathrm{a}}\right.$ in Scheme 1$)$ at $9.77 \mathrm{ppm}$ that integrates to a 1:3 ratio with the terminal $\mathrm{CH}_{3}$ protons (Fig. 7a). This peak is still seen in the bulk reaction products if any of the hexanal remains unreacted.
For the bulk acid-catalyzed reaction of hexanal in $\begin{array}{llllll}50 & \mathrm{wt} \% & \mathrm{H}_{2} \mathrm{SO}_{4} / 50 \mathrm{wt} \% & \mathrm{H}_{2} \mathrm{O} \text { and } 30 \mathrm{wt} \% & \mathrm{H}_{2} \mathrm{SO}_{4} /\end{array}$ $70 \mathrm{wt} \% \mathrm{H}_{2} \mathrm{O}$, a new peak appears at $4.85 \mathrm{ppm}$ that can be identified as either a proton alpha to the hydroxyl group $\left(H_{\mathrm{d}}\right)$ or an ether proton $\left(H_{\mathrm{e}}\right.$ and $\left.H_{\mathrm{f}}\right)$ (Fig. 7b). The peak is a clearly defined triplet and thus can be attributed to only one type of proton. The peak integrates in a 2:6 ratio with $\mathrm{CH}_{3}$ protons, which is predicted for the hemiacetal and trimer, though not polymer. In addition, the absence of an additional ether proton (i.e. $H_{\mathrm{e}}$ ) at $4-5 \mathrm{ppm}$ rules out the polymer as a reaction product. However, as both the trimer and hemiacetal have protons in similar chemical environments, $H_{\mathrm{f}}$ and $H_{\mathrm{d}}$ from Scheme 1 respectively, that integrate to the terminal methyl protons in a ratio of $1: 3$, FTIR spectroscopy was utilized to determine whether the hemiacetal or trimer was present. The FTIR spectrum of the dry unknown organic fraction from the bulk reaction of hexanal in $50 \mathrm{wt} \%$ sulfuric acid in water, shown in Fig. 8, shows a band in the $\mathrm{OH}$ stretching region $\left(3400-3500 \mathrm{~cm}^{-1}\right)$. The lack of the water bend at $\sim 1650 \mathrm{~cm}^{-1}$ suggests that the $\mathrm{OH}$ band is not due to residual condensed water and thus the band was attributed to the hydroxyl group on the hemiacetal.

Protons attached to heteroatoms, like oxygen, have variable chemical shifts dependent upon the molecule and broad or missing peaks dependent upon the exchange rate of the proton. No proton attributed to a hydroxyl group was seen in any spectrum; this was confirmed by performing a $\mathrm{D}_{2} \mathrm{O}$ exchange experiment. This experiment exchanges deuterium for hydrogen on a hydroxyl group, and thus a disappearance of a peak in the ${ }^{1} \mathrm{H}-\mathrm{NMR}$ spectrum will occur if a hydroxyl proton is present. No peak disappeared in our samples; therefore, no hydroxyl proton was measured, although it does not rule out the possibility that a hydroxyl group is present. Protons on heteroatoms are exchangeable and thus are in equilibrium with their unprotonated form. It is common that this exchange occurs too quickly and the proton cannot be measured through ${ }^{1}$ H-NMR (Vollhardt and Schore, 1994; Fox and Whitesell, 1997), thus the hemiacetal can still be present even though no hydroxyl group was seen in ${ }^{1} \mathrm{H}-\mathrm{NMR}$ spectra.

In bulk $75 \mathrm{wt} \%$ sulfuric acid and $96 \mathrm{wt} \%$ sulfuric acid in water, the hexanal reacts to form the aldol condensation product. The aldol product was identified by the shift in the aldehyde proton from $9.77 \mathrm{ppm}$ in hexanal $\left(H_{\mathrm{a}}\right)$ to $9.37 \mathrm{ppm}$ in the aldol $\left(H_{\mathrm{b}}\right)$, as well as the appearance of a vinyl proton at 


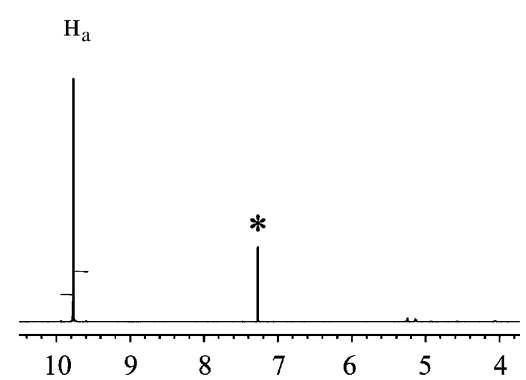

(A)

Chemical Shift (ppm)

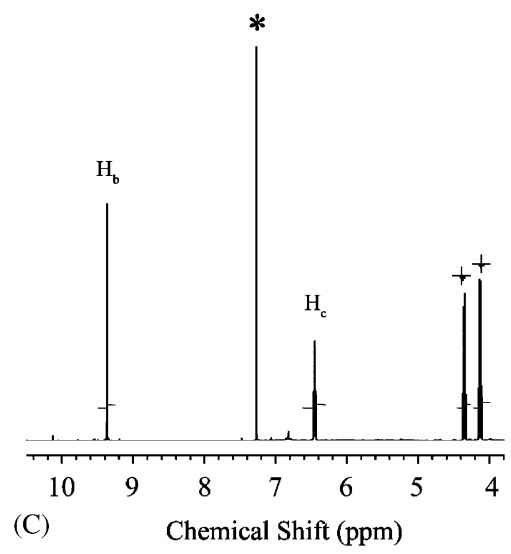

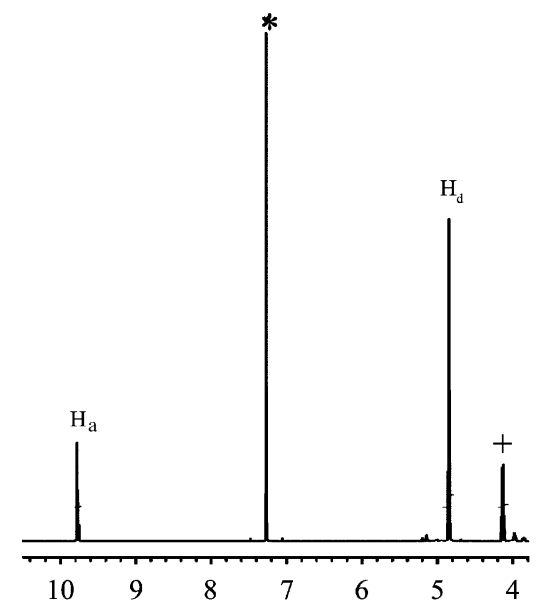

(B)

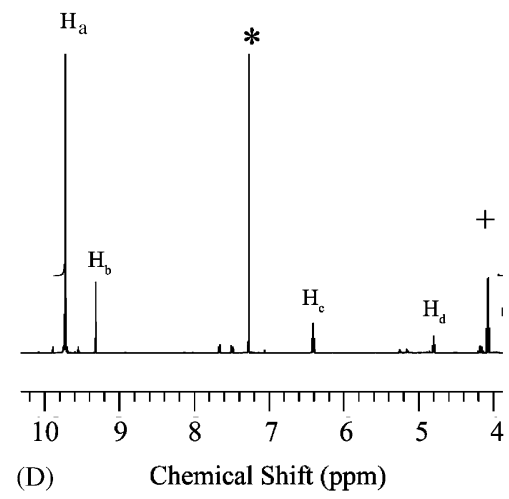

Fig. 7. ${ }^{1} \mathrm{H}-\mathrm{NMR}$ of (A) pure hexanal, (B) bulk reaction product of $50 \mathrm{wt} \% \mathrm{H}_{2} \mathrm{SO}_{4} / 50 \mathrm{wt} \% \mathrm{H}_{2} \mathrm{O}$ and hexanal, identified as hemiacetal and (C) bulk reaction product of $96 \mathrm{wt} \% \mathrm{H}_{2} \mathrm{SO}_{4} / 4 \mathrm{wt} \% \mathrm{H}_{2} \mathrm{O}$ and hexanal, identified as aldol condensation product, (D) aerosol reaction product of gas phase hexanal in $96 \mathrm{wt} \% \mathrm{H}_{2} \mathrm{SO}_{4} / 4 \mathrm{wt} \% \mathrm{H}_{2} \mathrm{O}$ aerosols. * indicates the peak for the solvent $\mathrm{CDCl}_{3}$ and + indicates peaks that a 2D-COSY experiment found are not from the reaction products, but rather contamination from the hexanal (D and B) and reaction of sulfuric acid with ethyl acetate $(\mathrm{C})$. The main peaks are labeled with the corresponding proton from Scheme 1 .

$6.45 \mathrm{ppm}\left(H_{\mathrm{c}}\right)$ (Fig. 7, panel C). The ratio of the aldehyde proton to vinyl proton to the terminal $\mathrm{CH}_{3}$ protons is $1: 1: 6$, again indicating that no polymer is present. Proton assignments were verified using a 2D-COSY experiment, through which the order of protons within the structure can be elucidated. This dependence of reaction mechanism on acidity would be predicted by Le Chatelier's Principle. In low acid concentration, there is more water available for the hydration of the aldehyde, driving the hemiacetal reaction forward. However, for the aldol condensation to occur, a dehydration must occur, which would be favorable at high acid concentrations.

After fully identifying the bulk reaction products, ammonium sulfate aerosols and sulfuric acid aero- sols (initial concentrations of 30, 50, 75, $96 \mathrm{wt} \%$ $\mathrm{H}_{2} \mathrm{SO}_{4}$ in water) were exposed to hexanal vapor at a partial pressure of $0.009 \mathrm{~atm}$. After reaction, the particles were collected by bubbling into a volume of ethyl acetate for $4 \mathrm{~h}$. The gas-phase hexanal was not removed prior to sampling and thus was evident in the collected organic fraction. The organic products were isolated and both ${ }^{1} \mathrm{H}-\mathrm{NMR}$ and GC-MS were performed on the collected aerosol samples. The data collected from the aerosol organic fraction was compared to the standards collected from bulk analysis to identify the reaction products. A control was performed to insure that no reaction was occurring during sampling. Hexanal vapor was flowed into a solution of $250 \mathrm{~mL}$ ethyl acetate and $1 \mathrm{mg}$ sulfuric acid, the calculated 


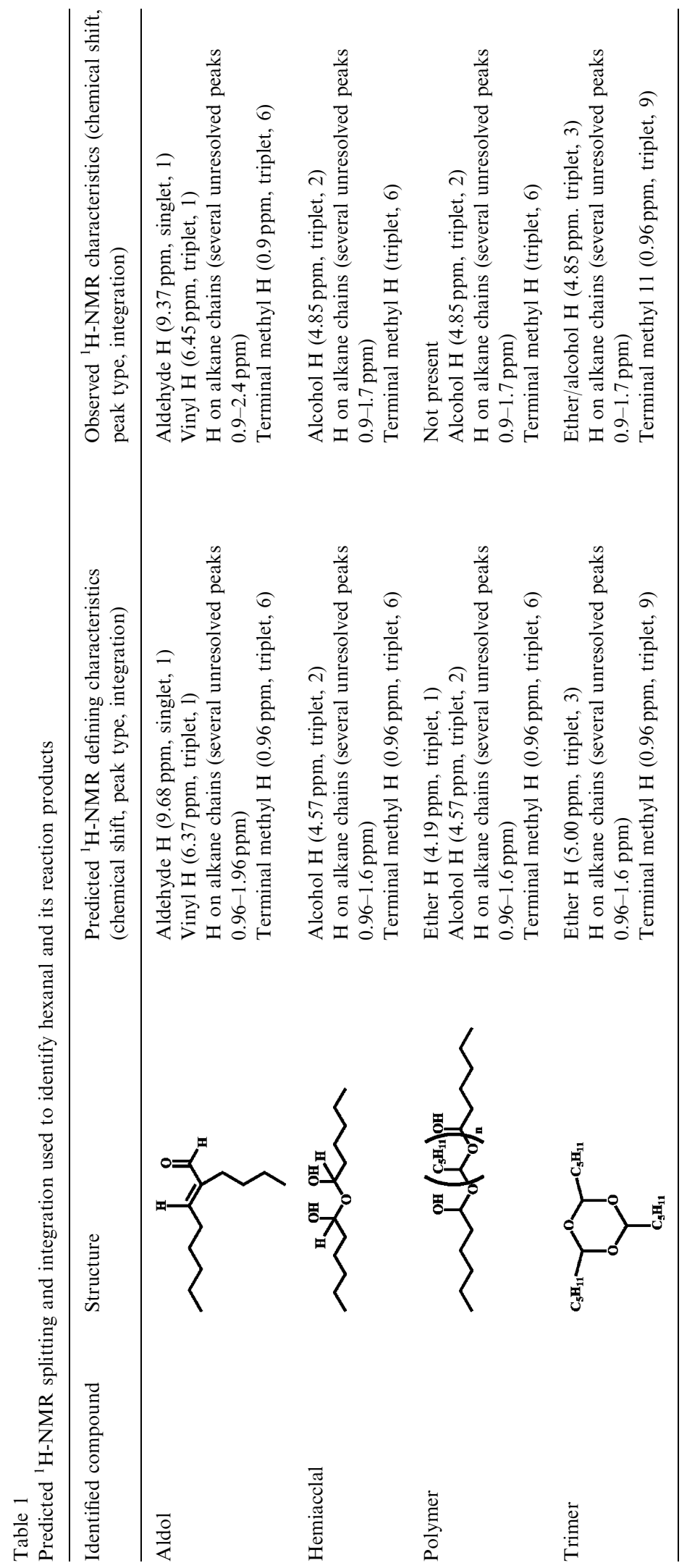




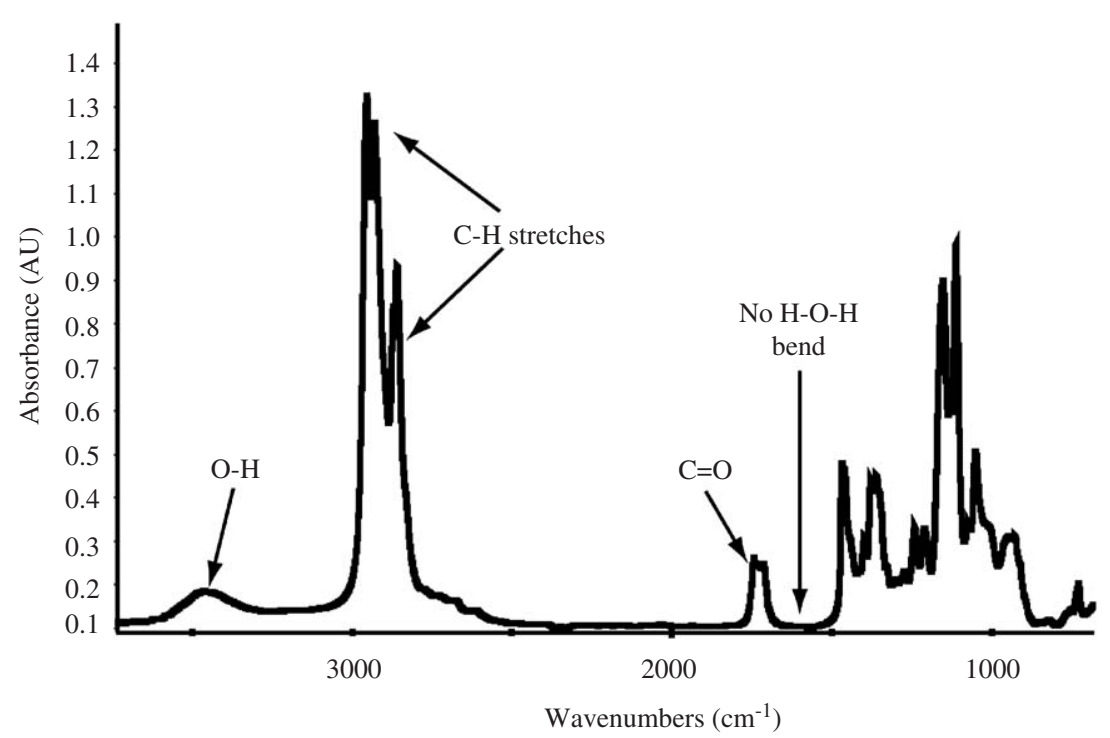

Fig. 8. FTIR spectrum of hemiacetal produced from bulk reaction of liquid hexanal in a $50 \mathrm{wt} \%$ sulfuric acid in water solution.

amount of collected aerosol, for $4 \mathrm{~h}$. No accretion reaction products were seen; thus, any accretion reaction products identified in the solution must have been produced in the aerosol.

Representative GC chromatographs from the collected aerosols are shown in Fig. 9. In the ammonium sulfate aerosols, panel A, no products of accretion reactions were formed, only hexanal and hexanoic acid. Hexanoic acid was found in all concentrations of sulfuric acid as well as in the ammonium sulfate aerosols and the blank, this leads us to believe that some of the gas-phase hexanal is oxidized in the collection process. Thus, hexanoic acid does not appear to be forming within the aerosols. Hexanal oxidizes easily to hexanoic acid as trace amounts are found in hexanal solutions exposed to air. The organic acid was not seen in the bulk studies because it was removed during the aqueous work up. The sulfuric acid aerosol chromatographs (Fig. 9B and C) all had a peak at $\sim 13$ min that had a mass spectrum inconsistent with any of the possible pathways indicated in Scheme 1. Using ${ }^{1} \mathrm{H}-\mathrm{NMR}$ data, which is a less destructive method of identifying compounds, the unknown compound in the GC-MS can be identified as the hemiacetal. Hemiacetals are somewhat unstable molecules, and thus most likely degraded on the GC column (Vollhardt and Schore, 1994; Fox and Whitesell, 1997). Only the chromatographs of the sulfuric acid aerosols with initial concentrations of 75 and $96 \mathrm{wt} \%$ in water had a peak at $9 \mathrm{~min}$. The mass spectrum associated with its peak is consistent with the NIST reference spectrum for the aldol condensation product, 2-butyl 2-octenal.

Fig. 7d displays a sample ${ }^{1} \mathrm{H}-\mathrm{NMR}$ spectrum of the reaction products of sulfuric acid aerosols with an initial sulfuric acid concentration of $96 \mathrm{wt} \%$ in water exposed to hexanal vapor. While in the bulk reaction this same concentration of acid produced only the aldol product, in the aerosol both the hemiacetal and aldol condensation product were formed. As in the bulk solutions, no polymerization was seen at any acid concentration. Only at the higher acid concentrations was the aldol produced, yet the hemiacetal was produced at all concentrations.

The bulk reactions, which were performed mainly to produce standards to test the product identification procedure, were not run under the exact conditions as the aerosol study and that may cause this difference in products for the aerosols with an initial sulfuric acid concentration of 75 and $96 \mathrm{wt} \%$ in water. The hexanal was not only more concentrated in the bulk study, but it was introduced as a liquid into a volume of aqueous sulfuric acid solution. As the mechanisms of these acid-catalyzed reactions are not fully understood, it is difficult to say what differences in the reaction mechanism, if any, will occur between the bulk solutions and the aerosol. The products identified in the aerosols in this study should be considered more atmospherically relevant. 
Table 2 summarizes the identification of the reaction products for the various initial concentrations of the sulfuric acid aerosols and ammonium
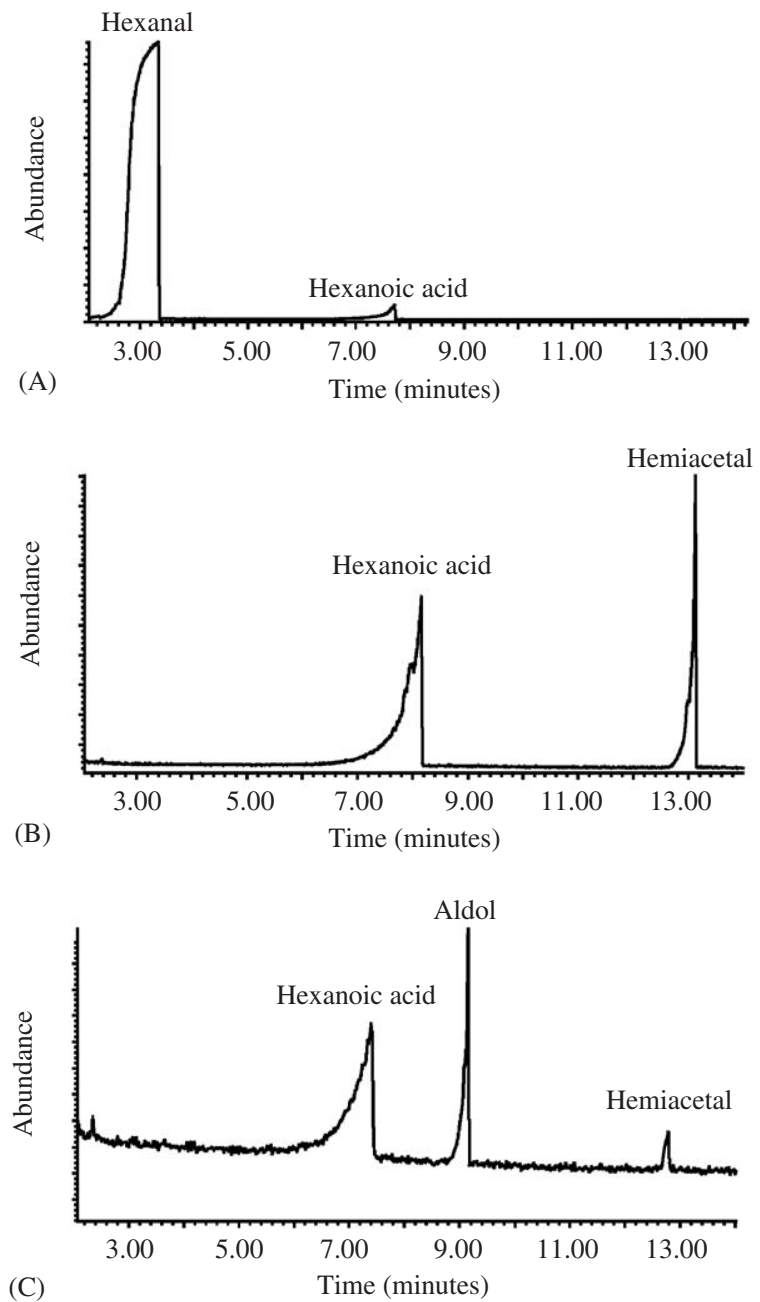

Fig. 9. GC-MS spectra of organic fraction of the collected aerosols of (A) ammonium sulfate, (B) $30 \mathrm{wt} \%$ sulfuric acid in water and (C) $75 \mathrm{wt} \%$ sulfuric acid in water all exposed to $0.009 \mathrm{~atm}$ of hexanal. The peak at $\sim 3 \mathrm{~min}$ is due to hexanal, at $\sim 7 \mathrm{~min}$ is due to hexanoic acid, at $\sim 9 \mathrm{~min}$ is due to the aldol condensation product, at $\sim 13 \mathrm{~min}$ is unidentified in GC-MS, but identified as hemiacetal through ${ }^{1} \mathrm{H}-\mathrm{NMR}$. sulfate based on both GC-MS and ${ }^{1} \mathrm{H}-\mathrm{NMR}$. It can be seen that the GC-MS and ${ }^{1} \mathrm{H}-\mathrm{NMR}$ give consistent results for the identity of the reaction products. No accretion reactions were observed in ammonium sulfate aerosols. Sulfuric acid aerosols with initial concentrations of 30 and $50 \mathrm{wt} \%$ in water produced the hemiacetal while aerosols with the initial concentration of 75 and $96 \mathrm{wt} \%$ sulfuric acid in water allowed for both hemiacetal and aldol condensation production. No polymerization was observed in any aerosols.

\subsection{Optical properties}

The acid-catalyzed reaction of hexanal to produce the aldol condensation product produced a yellow solution, presumably from the weakly allowed $n \rightarrow \pi^{*}$ $\mathrm{C}=\mathrm{O}$ absorption band (Bayliss and McRae 1954). UV-VIS spectra of the aldol condensation product and hexanal are shown in Fig. 10. While hexanal has no absorption features in the visible region, the long wavelength edge of the aldol spectrum extends into the visible region, leading to the observed yellow color of the product solution. This characteristic has been attributed to polymerization by others (Limbeck et al., 2003; Noziere and Esteve, 2005; Zhao et al., 2005). For example, Noziere and Esteve (2005) have suggested in the acid-catalyzed reaction of acetaldehyde the appearance of a product peak at $350 \mathrm{~nm}$ is due to the formation of three conjugated double bonds, which would occur if three acetaldehyde molecules reacted. In this study, ${ }^{1} \mathrm{H}-\mathrm{NMR}$ data indicates that no polymerization has occurred in the aldol condensation reaction of hexanal, implying that the conjugation in the aldol condensation product alone accounts for the color of the product. Therefore, acid-catalyzed reactions may be a route by which atmospheric organic compounds become absorptive in the visible region, and this aspect of aerosol processing could have implications for the radiative properties of such aerosols.

Table 2

Organic compounds identified in collected ammonium sulfate and sulfuric acid aerosols after exposure to hexanal vapor

\begin{tabular}{lll}
\hline $\begin{array}{l}\text { Weight percent sulfuric } \\
\text { acid aerosol (rest is water) }\end{array}$ & No. of peaks in GC-MS; identified as & Products identified in ${ }^{1} \mathrm{H}-\mathrm{NMR}$ \\
\hline $30 \mathrm{wt} \%$ & 3 peaks; hexanal, hexanoic acid and unknown & Hexanal, hexanoic acid and hemiacetal \\
$50 \mathrm{wt} \%$ & 3 peaks; hexanal, hexanoic acid and unknown & Hexanal, hexanoic acid and hemiacetal \\
$75 \mathrm{wt} \%$ & 4 peaks; hexanal, hexanoic acid, aldol and unknown & Hexanal, hexanoic acid aldol and hemiacetal \\
$96 \mathrm{wt} \%$ & 4 peaks; hexanal, hexanoic acid, aldol and unknown & Hexanal, hexanoic acid aldol and hemiacetal \\
Ammonium sulfate & 2 peaks; hexanal and hexanoic acid & Hexanal and hexanoic acid
\end{tabular}




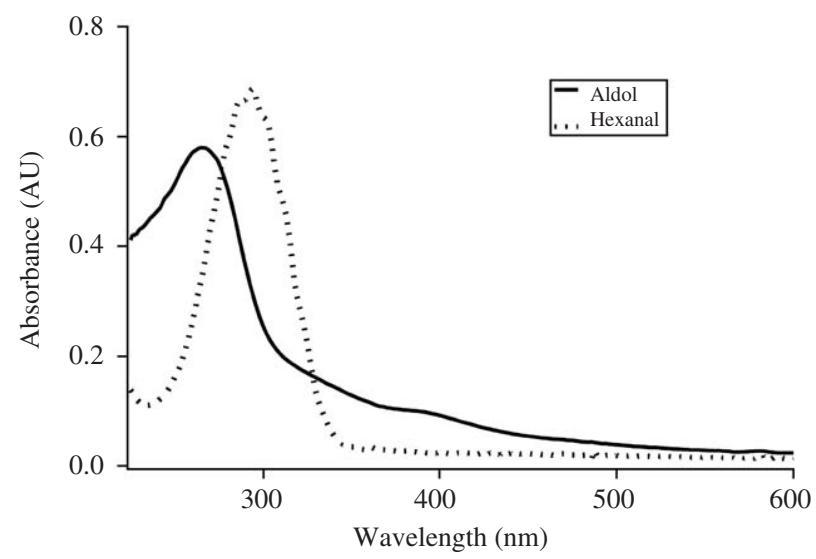

Fig. 10. UV-VIS spectra of hexanal (dotted line) and the aldol condensation product from bulk reaction of hexanal in $96 \mathrm{wt} \%$ sulfuric acid in water (solid line). Pathlength is $1 \mathrm{~cm}$. The concentration of aldol in the cuvette is $1.76 \times 10^{-3} \mathrm{M}$ and the hexanal is $2.56 \times 10^{-2} \mathrm{M}$. Molar absorptivity for the aldol peak $\sim 390 \mathrm{~nm}$ was found to be $56 \mathrm{M}^{-1} \mathrm{~cm}^{-1}$.

\section{Conclusions and atmospheric implications}

It has been suggested that polymerization (rather than the dimerization-type reactions reported here) of volatile organics is necessary for the organics to appreciably partition into aerosols. However, we have produced aerosols up to $89 \%$ organic by mass with no polymerization occurring. If the smaller aldehydes react similarly to hexanal and the products are restricted to dimer-like species, the vapor pressure of the products will not be low enough to partition into the particles, and thus the smaller and more atmospherically abundant aldehydes might not contribute to the addition of organic mass into aerosols. On the other hand, if simple dimerization reactions can explain the presence of organic material in aerosols, the kinetics of the process is likely more facile than a multi-step polymerization process. In any case, our results indicate that aldehydes as small as the $\mathrm{C}_{4}$ compound butanal may be able to partition to aerosols through acid-catalyzed reactions. The dimer product of any compound smaller than butanal would still have too high of vapor pressure to partition greatly into the particle. In addition, we have shown that the acidcatalyzed reactions of hexanal have the result of producing species that have absorption features in the visible region of the spectrum. If these species were significant in atmospheric aerosols, the radiative properties of such particles would be modified.

\section{Acknowledgements}

We thank Dr. Richard Shoemaker for training on the ${ }^{1} \mathrm{H}-\mathrm{NMR}$, Dr. John Hagadorn for the use of his FTIR spectrometer and Jessica Gilman for training on the GC-MS. This research was supported by the Office of Science (BER), US Department of Energy, Grant No. DE-FG0201ER63096. KK was supported by a HHMI predoctoral fellowship. MJE was supported by sabbatical grants from the American Chemical Society Petroleum Research Fund and the Mellon Foundation.

\section{References}

Alfarra, M.R., Coe, H., et al., 2004. Characterization of urban and rural organic particulate in the lower Fraser valley using two aerodyne aerosol mass spectrometers. Atmospheric Environment 38, 5745-5758.

Allan, J., Delia, A., et al., 2004. A generalised method for the extraction of chemically resolved mass spectra form Aerodyne aerosol mass spectrometer data. Journal of Aerosol Science 35, 909-922.

Anthony, S.E., Tisdale, R.T., et al., 1995. FTIR studies of lowtemperature sulfuric-acid aerosols. Geophysical Research Letters 22, 1105-1108.

Barsanti, K.C., Pankow, J.F., 2004. Thermodynamics of the formation of atmospheric organic particulate matter by accretion reactions-Part 1: aldehydes and ketones. Atmospheric Environment 38, 4371-4382.

Barsanti, K.C., Pankow, J.F., 2005. Thermodynamics of the formation of atmospheric organic particulate matter by accretion reactions - 2. Dialdehydes, methylglyoxal, and diketones. Atmospheric Environment 39, 6597-6607.

Bayliss, N., McRae, E., 1954. Solvent effects in the spectra of acetone, crotonaldehyde, nitromethane and nitrobenzene. Journal of Physical Chemistry 58, 1006-1111.

Bertram, A.K., Patterson, D.D., et al., 1996. Mechanisms and temperatures for the freezing of sulfuric acid aerosols measured by FTIR extinction spectroscopy. Journal of Physical Chemistry 100, 2376-2383. 
Brock, C.A., Trainer, M., et al., 2003. Particle growth in urban and industrial plumes in Texas. Journal of Geophysical Research-Atmospheres 108.

Brock, C.A., Washenfelder, R.A., et al., 2002. Particle growth in the plumes of coal-fired power plants. Journal of Geophysical Research-Atmospheres 107.

Bruch, M., 1996. Multidimensional NMR Spectroscopy of Liquids. Marcel Dekker Inc, NY.

Carey, F., Sundberg, R., 1990. Advanced Organic Chemistry. Plenum Press, NY.

Chu, S.H., Paisie, J.W., et al., 2004. PM data analysis-a comparison of two urban areas: Fresno and Atlanta. Atmospheric Environment 38, 3155-3164.

Czoschke, N.M., Jang, M., et al., 2003. Effect of acidic seed on biogenic secondary organic aerosol growth. Atmospheric Environment 37, 4287-4299.

Fox, M.A., Whitesell, J.K., 1997. Organic Chemistry. Jones and Bartlett Publishers, Boston.

Iinuma, Y., Boge, O., et al., 2004. Aerosol-chamber study of the alpha-pinene/O-3 reaction: influence of particle acidity on aerosol yields and products. Atmospheric Environment 38, 761-773.

Iraci, L.T., Tolbert, M.A., 1997. Heterogeneous interaction of formaldehyde with cold sulfuric acid: Implications for the upper troposphere and lower stratosphere. Journal of Geophysical Research-Atmospheres 102, 16099-16107.

Jang, M., Lee, S., et al., 2003a. Organic aerosol growth by acidcatalyzed heterogeneous reactions of octanal in a flow reactor. Atmospheric Environment 37, 2125-2138.

Jang, M.S., Carroll, B., et al., 2003b. Particle growth by acidcatalyzed heterogeneous reactions of organic carbonyls on preexisting aerosols. Environmental Science and Technology 37, 3828-3837.

Jang, M.S., Czoschke, N.M., et al., 2002. Heterogeneous atmospheric aerosol production by acid-catalyzed particle-phase reactions. Science 298, 814-817.

Jang, M.S., Czoschke, N.M., et al., 2005. Semiempirical model for organic aerosol growth by acid-catalyzed heterogeneous reactions of organic carbonyls. Environmental Science and Technology 39, 164-174.

Jang, M.S., Kamens, R.M., 2001. Atmospheric secondary aerosol formation by heterogeneous reactions of aldehydes in the presence of a sulfuric acid aerosol catalyst. Environmental Science and Technology 35, 4758-4766.

Jayne, J., Leard, D., et al., 2000. Development of an aerosol mass spectrometer for size and composition analysis of submicron particles. Aerosol Science and Technology 33, 49-70.

Jimenez, J.L., Jayne, J.T., et al., 2003. Ambient aerosol sampling using the Aerodyne aerosol mass spectrometer. Journal of Geophysical Research-Atmospheres 108, 8424.

Kalberer, M., Paulsen, D., et al., 2004. Identification of polymers as major components of atmospheric organic aerosols. Science 303, 1659-1662.

Kamens, R.M., Jang, M., et al., 1999. Aerosol formation from the reaction of alpha-pinene and ozone using a gas-phase kinetics-aerosol partitioning model. Environmental Science and Technology 33, 1430-1438.

Kawamura, K., Steinberg, S., et al., 2000. Homologous series of C-1-C-10 monocarboxylic acids and C-1-C-6 carbonyls in Los Angeles air and motor vehicle exhausts. Atmospheric Environment 34, 4175-4191.
Kesselmeier, J., Staudt, M., 1999. Biogenic volatile organic compounds (VOC): an overview on emission, physiology and ecology. Journal of Atmospheric Chemistry 33, 23-88.

Liggio, J., Li, S.M., et al., 2005. Heterogeneous reactions of glyoxal on particulate matter: identification of acetals and sulfate esters. Environmental Science and Technology 39, $1532-1541$.

Limbeck, A., Kulmala, M., et al., 2003. Secondary organic aerosol formation in the atmosphere via heterogeneous reaction of gaseous isoprene on acidic particles. Geophysical Research Letters 30.

Martin, G., Zektzer, A., 1988. Two-dimensional NMR Methods for Establishing Molecular Connectivity. VCH Publishers Inc, NY.

Michelsen, R.R., Ashbourn, S.F.M., et al., 2004. Dissolution, speciation, and reaction of acetaldehyde in cold sulfuric acid. Journal of Geophysical Research-Atmospheres 109 .

Middlebrook, A.M., Murphy, D.M., et al., 1998. Observations of organic material in individual marine particles at Cape Grim during the First Aerosol Characterization Experiment (ACE 1). Journal of Geophysical Research 103, 16475-16483.

Middlebrook, A.M., Thomson, D.S., et al., 1997. On the purity of laboratory-generated sulfuric acid droplets and ambient particles studied by laser mass spectrometry. Aerosol Science and Technology 27, 293-307.

Molnar, A., Meszaros, E., et al., 1999. The importance of organic and elemental carbon in the fine atmospheric aerosol particles. Atmospheric Environment 33, 2745-2750.

Muller, K., Pelzing, M., et al., 2002. Monoterpene emissions and carbonyl compound air concentrations during the blooming period of rape (Brassica napus). Chemosphere 49, $1247-1256$.

Noziere, B., Esteve, W., 2005. Organic reactions increasing the absorption index of atmospheric sulfuric acid aerosols. Geophysical Research Letters 32.

Noziere, B., Riemer, D.D., 2003. The chemical processing of gas-phase carbonyl compounds by sulfuric acid aerosols-2,4-pentanedione. Atmospheric Environment 37, 841-851.

Saxena, P., Hildemann, L.M., 1996. Water-soluble organics in atmospheric particles: a critical review of the literature and application of thermodynamics to identify candidate compounds. Journal of Atmospheric Chemistry 24, 57-109.

Tadic, J., Juranic, I., et al., 2001. Photooxidation of $n$-hexanal in air. Molecules 6, 287-299.

Takegawa, N., Miyazaki, Y., et al., 2005. Characterization of an Aerodyne aerosol mass spectrometer (AMS): intercomparison with other aerosol instruments. Aerosol Science and Technology 39, 760-770.

Tolocka, M.P., Jang, M., et al., 2004. Formation of oligomers in secondary organic aerosol. Environmental Science and Technology 38, 1428-1434.

Turpin, B.J., Saxena, P., et al., 2000. Measuring and simulating particulate organics in the atmosphere: problems and prospects. Atmospheric Environment 34, 2983-3013.

Vollhardt, K.P.C., Schore, N.E., 1994. Organic Chemistry. WH Freeman and Company, New York.

Zhang, K.M., Wexler, A.S., 2002. A hypothesis for growth of fresh atmospheric nuclei. Journal of Geophysical ResearchAtmospheres 107. 
Zhang, Q., Canagaratna, M.R., et al., 2005. Time- and size-resolved chemical composition of submicron particles in Pittsburgh: Implications for aerosol sources and processes. Journal of Geophysical Research-Atmospheres 110.
Zhang, R.Y., Suh, I., et al., 2004. Atmospheric new particle formation enhanced by organic acids. Science 304, 1487-1490.

Zhao, J., Levitt, N., et al., 2005. Heterogeneous chemistry of octanal and 2,4-hexadienal with sulfuric acid. Geophysical Research Letters 32. 